\title{
Identification of protein kinase G I alpha interacting proteins as potential targets to prevent cardiac remodeling
}

\author{
Robert Blanton ${ }^{1 *}$, Angela Lane ${ }^{1}$, Mark Aronovitz ${ }^{1}$, Guang-Rong Wang ${ }^{1}$, Robrecht Thoonen ${ }^{1}$, Roger Davis ${ }^{2}$, \\ Michael Mendelsohn ${ }^{1,3}$, David Kass ${ }^{4}$, Richard Karas ${ }^{1}$ \\ From 6th International Conference on cGMP: Generators, Effectors and Therapeutic Implications \\ Erfurt, Germany. 28-30 June 2013
}

\section{Background}

We recently reported that mutation of the cGMP-dependent Protein Kinase G I alpha (PKGI $\alpha$ ) N-terminal leucine zipper (LZ) domain (in the PKGIa LZ mutant, or LZM, mouse) accelerates cardiac remodeling and heart failure after left ventricular (LV) pressure overload, and prevents the anti-remodeling effect of sildenafil [1]. We therefore hypothesized that PKGI $\alpha$ attenuates remodeling by regulating cardiac signaling pathways that are dependent on substrate interactions mediated by its LZ domain. As a first step to identifying cardiac proteins downstream of PKGI $\alpha$, we screened myocardial lysates for PKGI $\alpha$ LZ domain-interacting proteins. Our previous work revealed a requirement for the PKGI $\alpha$ LZ domain for the activation of anti-remodeling myocardial JNK activity after LV pressure overload. MLK3 is a MAPKKK that contains an LZ domain and activates JNK.

\section{Results}

We now demonstrate, by immunoprecipitation, that MLK 3 interacts with the PKGI $\alpha$ LZ domain in myocardial lysates. We show further that 8-Br-cGMP induces MLK3 phosphorylation on Thr277 and Ser281 in WT, but not LZM lysates. And, in 293 cells transfected with FLAGMLK3, 8Br-cGMP induced PKGIa-MLK3 co-precipitation, and increased MLK3 phosphorylation on Thr277/Ser281. Co-transfection of MLK3 and PKGI $\alpha$ also induced MLK3 phosphorylation. We next examined the cardiovascular effect of MLK3 deletion in vivo. Male 8 week old MLK3-/mice display basal bi-ventricular hypertrophy compared

\footnotetext{
* Correspondence: rblanton@tuftsmedicalcenter.org

'Molecular Cardiology Research Institute, Tufts Medical Center, Boston, MA, USA

Full list of author information is available at the end of the article
}

with littermate controls (LV/Tibia length $42.8 \pm 0.6 \mathrm{mg} / \mathrm{cm}$ in WT, $52.9 \pm 1.8$ in MLK3 $-/$-; $P<0.01$; RV/TL $10.8 \pm 0.1$ $\mathrm{mg} / \mathrm{cm}$ in WT, $13.3 \pm 0.3$ in MLK3-/-; $P<0.01 ; \mathrm{n}=7 \mathrm{WT}$, 5 MLK3-/-). By 14-16 weeks of age, LVH progressed in the MLK3-/- mice (LV/TL $47.7 \pm 1.3 \mathrm{mg} / \mathrm{cm}$ in WT, $59.8 \pm$ 7.5 in MLK3-/-; $\mathrm{n}=6$ WT, 9 MLK3-.-; $P<0.01)$. Arterial blood pressure was modestly increased, though still normal, in MLK3-/- mice (SBP $93 \pm 1$ in WT, $113 \pm 1$ in MLK3-/-). And, 14-16 week MLK3-/- mice have impaired LV diastolic function (tau $3.2 \pm 0.1 \mathrm{~ms}$ WT, $3.7 \pm 0.1$ MLK3-/-; P 0.06).

\section{Conclusion}

Our studies reveal a novel function of MLK3 as a myocardial PKGI $\alpha$ effector and inhibitor of LVH. These results support the strategy of exploring LZ-dependent PKGI $\alpha$ substrates in the myocardium to identify potential therapeutic targets for cardiac remodeling.

\section{Authors' details \\ ${ }^{1}$ Molecular Cardiology Research Institute, Tufts Medical Center, Boston, MA, USA. ${ }^{2}$ Department of Biochemistry, University of Massachusetts School of Medicine, Worcester, MA, USA. '3Merck Pharmaceuticals, Rahway, NJ, USA. ${ }^{4}$ Department of Cardiology, Johns Hopkins Medical Institutions, Baltimore, $M D$, USA.}

Published: 29 August 2013

\section{Reference}

1. Blanton R, Takimoto, Lane AM, Aronovitz M, Piotrowski R, Karas RH, Kass DA, Mendelsohn ME: Protein kinase $g$ ia inhibits pressure overloadinduced cardiac remodeling and is required for the cardioprotective effect of sildenafil in vivo. J Am Heart Assoc 2012, 1:e003731.

doi:10.1186/2050-6511-14-S1-P10

Cite this article as: Blanton et al:: Identification of protein kinase G I alpha interacting proteins as potential targets to prevent cardiac remodeling. BMC Pharmacology and Toxicology 2013 14(Suppl 1):P10.

\section{Biomed Central}

C 2013 Blanton et al; licensee BioMed Central Ltd. This is an Open Access article distributed under the terms of the Creative Commons Attribution License (http://creativecommons.org/licenses/by/2.0), which permits unrestricted use, distribution, and reproduction in any medium, provided the original work is properly cited. 